\title{
PERCEPCIONES SOBRE LA FEMINEIDAD Y SUS IMPLICACIONES VOCACIONALES EN MUJERES ADOLESCENTES
}

\author{
Laura Mora Zúñiga \\ Gabriela Muñoz Porras \\ Cecilia Villarreal Montoya
}

Recibido 26-IX-2001 • Aceptado 4-XII-2001

\begin{abstract}
Resumen: El artículo presenta resultados de una investigación cuyo objeto de estudio fue un grupo de mujeres estudiantes de especialidades técnicas tradicionalmente reconocidas como masculinas.

Identifica algunas de las razones por la cuales estas jóvenes eligen estudiar en un colegio técnico y especializarse en esos oficios. Concluye que es necesario continuar profundizando en las posibilidades y condiciones de toma de decisiones en la dinámica familiar, las condiciones y oportunidades que brindan las instituciones a las adolescentes de estas y otras especialidades, el número de relaciones y la opinión docentealumno en estos centros educativos.
\end{abstract}

\section{Introducción}

La socialización es crucial en la adquisición de las características genéricas que la cultura ha construido a través de su historia tanto para mujeres como para hombres. Cada sociedad define formas de comportamiento masculino y femenino que expresan la concepción de mundo y las formas para la convivencia e interacción humana.

Esta concepción de mundo, pese a sus evoluciones, continúa definiendo en gran medida las elecciones vocacionales y laborales que realizan los hombres y las mujeres. El mundo genérico, en opinión de Lagarde (1995), ha sido conformado de manera binaria, con dos opciones que encierran cualidades, funciones y especializaciones femeninas y masculinas excluyentes entre sí.

La organización y administración del sistema educativo formal y no formal, así como las oportunidades laborales reflejan inequidad y discriminación al basarse en el desarrollo de habilidades, la designación de tareas, la definición de roles y responsabilidades, de acuerdo al sexo, de ahí que no es casual la designación de oficios para mujeres y para hombres. 
"La femineidad y la masculinidad no son elementos que se pueden poner y quitar a voluntad, sino que son la cultura concreta para el género en el sujeto" ( Lagarde, M. 1992, p. 24). El trato desigual que reciben las jóvenes por el hecho de ser mujeres, puede limitar la expresión de su identidad, y el resultado es un aprendizaje que las obliga a posponer sus aspiraciones de ejercicio profesional para asumir responsabilidades familiares (Spencer y Sanguiliano en Zunker, 1990).

En la adolescencia, las jóvenes buscan mayor independencia e inician el proceso de concepción de sí mismas como personas separadas de las figuras progenitoras. Se inicia entonces un proceso más consciente de elaboración de formas de pensamiento y de actuación más autónoma, lo cual implica necesariamente la búsqueda y producción de ideales, creencias y valores personales. Esta es una época para profundizar sobre quién se es y sobre lo que se quiere llegar a ser en el futuro; por ello, precisamente esta etapa de vida facilita la identificación de intereses y la cristalización de las preferencias vocacionales (Osipow, 1991).

Resulta interesante que, aunque las mujeres son orientadas dentro del esquema de la tradición, que feminiza sus opciones de estudio y trabajo; algunas de ellas rompen este esquema, cuestionan la tradición e inician estudios en carreras técnicas en áreas denominadas como masculinas.

Esta situación lleva a cuestionar sus experiencias de vida, preferencias, intereses y elecciones vocacionales, mensajes de personas significativas; buscando clarificar cómo las jóvenes logran a través de su elección reflejar su autoconcepto vocacional en un ambiente educativo-ocupacional masculinizado y conformado mayoritariamente por hombres.

Con el fin de conocer estas vivencias se realizó la investigación: "Percepciones sobre la femineidad y sus implicaciones vocacionales en mujeres adolescentes", estudio realizado con un grupo de nueve jóvenes estudiantes de undécimo año de tres Instituciones de Educación Técnica de San José en especialidades técnicas tradicionalmente reconocidas como masculinas.

Es objetivo del presente artículo compartir los resultados de este estudio que contó con el aval del Programa de Investigación en Educación y Género (PIEG) del Instituto de Investigación para el Mejoramiento de la Educación Costarricense (IIMEC).

Las interrogantes que sustentan la investigación son las siguientes:

1. ¿Cómo conciben la femineidad y el ser mujer este grupo de jóvenes adolescentes y cómo ha influido la propia historia de vida en la construcción de esos significados?

2. ¿Qué motivaciones tienen estas jóvenes para estudiar en el Sistema de Educación Técnica y especializarse en oficios reconocidos como masculinos?

3. ¿Qué situaciones deben enfrentar en el proceso de formación en esas especialidades?

Para responder a estas preguntas, se realizó un acercamiento cualitativo que permite profundizar en el significado que las personas le dan a sus vivencias (Taylor y Bodgan, 1990), en este caso a las nueve estudiantes de: electrónica industrial, electromecánica, mecánica automotriz de precisión y general; electrónica en reparación de equipo de cómputo, microelectrónica, refrigeración y aire acondicionado, y construcción civil.

\section{Acercamiento teórico}

El nacer con una definición biológica como mujer o como hombre, pareciera ser razón suficiente para heredar roles, funciones y patrones de comportamiento que 
llevan implícitas formas de vida masculinas y femeninas.

Nuestra sociedad estructura y organiza sus instituciones y a las personas que las integran en un sistema compacto que crea y recrea la cultura patriarcal, la cual sobrevalora a los hombres y lo masculino al mismo tiempo que desvaloriza e invisibiliza lo femenino y a las mujeres. El patriarcado, entendido como el orden social de supremacía masculina está tan profundamente arraigado que no requiere justificación: "se impone a sí mismo como autoevidente, y es tomado como natural gracias al acuerdo casi perfecto e inmediato que obtiene de, por un lado, estructuras sociales como la organización social del espacio y tiempo y la división sexual del trabajo, y por otro lado, de estructuras cognitivas inscritas en los cuerpos y en las mentes" (Bourdieu en Lamas, 1997, p. 345).

La caracterización sexista y estereotipada de la femineidad y la masculinidad lleva implícita una base de creencias referidas a los varones y a las mujeres como bloques monolíticos y claramente diferenciados entre sí. Se designan atributos, funciones y patrones para cada sexo, donde la dimensión instrumental corresponde al estereotipo masculino e incluye una serie de rasgos, tales como objetividad, dominio o competencia, que describen, en conjunto, a una persona que se maneja individualmente con eficacia. El estereotipo femenino, se identifica con una dimensión afectiva, representada por rasgos tales como la calidez, la expresividad y la sensibilidad, características de quienes se interesan más por las personas que por las cosas (Barberá, en Fernández, 1998).

Esta caracterización inevitablemente conlleva en forma implícita y explícita la diferenciación de roles y además explica la distribución del trabajo entre hombres y mujeres, la cual marca las elecciones vocacionales y la actividad laboral. No es casual que históricamente se haya mantenido una clasificación de carreras y puestos de tra- bajo y salarios diferenciados para hombres y para mujeres.

La incorporación de estos estereotipos sociales en la identidad individual se va logrando por medio de los procesos educativos formales, no formales e informales, a lo largo de la vida que socializa a las personas para formar parte de la colectividad. "La persona se va configurando, va llegando a ser en un desarrollo y frente a la sociedad como su particularidad individual" (Baró, 1990, p. 115). Es en este intercambio dinámico y profundo de interacción persona-contexto, que se va asimilando y construyendo una concepción de mundo social y una forma individual de enfrentarlo, crearlo, recrearlo, y de realizar cambios significativos para las personas y para la colectividad.

Este proceso de ser personas se inicia en el núcleo familiar, allí es donde "son enseñados y aprendidos los valores y las normas sociales, incluyendo las relaciones con la condición genérica" (Kourany; Sterba y Tong, 1999, p. 7). Desde que se nace, y por el trato diferenciado para hombres y mujeres, ya alrededor de los tres años se tiene claridad sobre el valor social y afectivo de la masculinidad y la femineidad y sobre el deber ser y el comportamiento "propio" de cada sexo, (Lamas, 1996; Wood, 1999; Bravo, 1996). En otras palabras, desde muy corta edad se captan las señales y la simbología genérica en el seno de las familias, en el centro infantil, en los medios de comunicación, en la literatura, en fin, en el modelaje y las relaciones genéricas donde quiera que estemos.

Desde el nacimiento, las figuras progenitoras asignan características a sus bebés basándose en los estereotipos socioculturales. A las niñas se les describe como "pequeñitas, tiernas y delicadas y para los varones utilizan adjetivos como fuertes y despiertos" (Kourany; Sterba y Tong, 1999, p. 7). Un aspecto interesante que estas autoras destacan es el hecho de que los padres utilizan más características estereotipadas que las madres para describir a sus bebés. 
Conforme avanza la crianza de la prole se va haciendo más evidente la influencia sociocultural en la definición de estilos de vida genéricos, reforzando en las niñas las relaciones e interacción social, el desarrollo motor fino al mismo tiempo que se tiende a pensar que las niñas necesitan más ayuda que los niños. Mientras que a éstos se les estimula el uso de la fuerza, el desarrollo motor grueso y el desarrollo físico y la independencia (Kourany; Sterba y Tong, 1999). Y desestimándose en los varones las conductas estereotipadas como femeninas y en las niñas las masculinas. Las familias van estimulando intereses, desarrollando habilidades, dirigiendo el desarrollo vocacional y transmitiendo expectativas sobre las preferencias profesionales de hombres y mujeres.

Este mismo patrón de desarrollo genérico es estimulado por los centros de educación formal, por medio de la administración de la institución educativa, el curriculum, los conocimientos que imparten, el material de apoyo, los procedimientos y las técnicas didácticas utilizadas en el aula. Según Bravo (1996), a pesar de los esfuerzos realizados por aminorar la educación sexista en Puerto Rico, las instituciones educativas continúan siendo reproductoras de la cultura patriarcal.

Las mujeres reciben menos atención, dedicación, tiempo y retos de parte de docentes (Hall \& Sanders, 1984 y Sandler \& Hall, 1986 en Wood, 1999). A ellas se les valora por ser calladas y complacientes, mientras que a los varones se les estimula y reconoce sus intereses personales y el esfuerzo académico. Además, las mujeres son estimuladas a estudiar carreras poco "retantes", menos demandantes y más bien se les estimula a centrarse en la familia (Wood,1999). Esta situación induce a nuestra realidad actual cual es, la concentración de hombres en la carreras universitarias en áreas relacionadas con el desarrollo económico, político, tecnológico e industria, versus una concentración de mujeres en Humanidades, Ciencias Sociales, Educación y Enfermería (Delgadillo, 1996).

A pesar de esta situación sabemos muy bien que cada vez más mujeres han ido ampliando sus funciones genéricas, incorporándose a áreas de estudio y de trabajo tradicionalmente denominadas como masculinas, y alcanzando niveles de prestigio importantes y ampliar sus roles y funciones asignados por la tradición patriarcal.

La apertura y flexibilidad hacia formas de vida menos estereotipadas permitirá a mujeres y hombres la toma de decisiones educativas, vocacionales y familiares basadas cada vez más en sus propios intereses y capacidades y no tanto en la estereotipia. La esperanza en el cambio permite soñar con un mundo mejor, tal y como lo plantea (Lagarde, 1997, p. 23), cuando afirma: "El mundo se conmueve con las voces de nuevos sujetos que no aceptan el sentido impuesto a la vida social y a la cotidianidad y replantean el orden".

\section{La identidad vocacional-ocupacional en mujeres adolescentes}

La etapa de la adolescencia como período del desarrollo, enfrenta a las mujeres a una serie de demandas personales y sociales que inciden en la percepción de sí mismas, en su rol y posición como mujeres jóvenes y en las expectativas personales, vocacionales y sociales que se planteen.

Almanza y otras (1997), opinan que las mujeres adolescentes tienen urgencia de incorporar a su identidad los cambios físicos, psicológicos y sociales que están experimentando, al tiempo que pueden confrontar lo aprendido y asignado por las distintas instituciones socializadoras tales como las familias, religiones, instituciones educativas y medios de comunicación, para enlazar sus experiencias como niñas y adolescentes en el proceso de elaboración identitaria. 
Esta construcción identitaria recibe la influencia de la sociedad patriarcal la cual define una serie de roles y tareas exclusivas y excluyentes para hombres y mujeres, jerarquiza sus espacios y ha construido un mundo genérico binario y opresivo que limita la realización de ambos (Lamas, 1997).

Al respecto, Suárez (1989) indica que las mujeres se relacionan consigo mismas y con su contexto asumiendo el estereotipo de la femineidad, ya que sus intereses, necesidades y capacidades personales son anuladas al esperar que respondan a todo lo que beneficie el desarrollo de los hombres, quienes aprenden a ser para sí mismos y a responder a sus intereses y necesidades. Las jóvenes descubren que los hombres tienen el poder único, los privilegios, mientras que para ellas la opción es convertirse en objetos sumisos y adorados, motivo por el cual surge el conflicto entre la autonomía y la necesidad que hace a las mujeres "dejar de ser" y comenzar a "parecer" (Pipher, 1997).

La cultura patriarcal ha reproducido un conjunto de creencias y comportamientos que definen para las mujeres un mundo privado dentro de la casa donde, en respuesta al "deber ser", las mujeres están sujetas a compartir la comida, los sueños y a servir a los hombres quienes se encargan del mundo público caracterizado por el poder, éxito, producción, dinero, conocimiento y la posibilidad de desarrollarse como personas independientes (Bolaños, 1993).

Las jóvenes encuentran pocas posibilidades de elaborar una identidad propia y visualizarse como personas independientes capaces de cumplir roles distintos a los de novias, esposas, compañeras y madres, sino que más bien centran su identidad en la belleza física, el erotismo y la procreación (Lagarde, 1995).

La influencia de la cultura patriarcal está presente en diversas áreas del desarrollo humano, sin dejar de lado el aspecto vocacional que para Osipow (1990) lleva a la persona a sintetizar sus experiencias de vida las cuales están mediatizadas por el contexto sociocultural en que interactúa. De ahí se infiere que el desarrollo vocacional está mediatizado por los elementos que conforman la cultura machista, patriarcal y misógina, siendo el género un condicionante de las preferencias ocupacionales o profesionales de hombres y mujeres.

En opinión de Super citado por Osipow (1990), las adolescentes en el área vocacional han de asumir la tarea básica de cristalizar sus preferencias, eligiendo la profesión u oficio que les gustaría desempeñar en el futuro. La cristalización implica cuestionarse cuál es el trabajo más apropiado, explorar los recursos que el medio ofrece, las necesidades e intereses personales, formular las propias preferencias vocacionales para luego implementar una de ellas. Todo ello debe darse, teniendo conciencia de los elementos que puedan afectar el logro de las metas, y apropiándose de la información requerida.

\section{La elección vocacional en mujeres adolescentes}

Es en la etapa de la adolescencia donde el desarrollo vocacional como proceso evolutivo mediatizado por el contexto sociocultural, se hace especialmente visible en el intento de responder a las nuevas demandas que surgen en dicho período.

La conducta vocacional por tanto, es producto de la interacción entre elementos como la familia, el mundo laboral, los estereotipos profesionales, la estructura económica, el sistema educativo, los factores situacionales, la historia de vida personal, el género, los intereses, las actitudes y la toma de decisiones (Rivas, 1995).

Autores como Rivas (1995), Holland (1990), y Roe citada por Osipow (1990), indican que el contexto familiar y los patrones vocacionales que en el mismo se modelan, se asocian directamente con las preferencias vocacionales de los miembros de la familia. 
El proceso de la identificación desempeña un papel decisivo en el desarrollo vocacional ya que de esta forma se adquieren las normas culturales que se esperan de acuerdo al sexo, practicándose por medio del juego y en la diversidad de experiencias cotidianas los patrones vocacionales modelados por las figuras progenitoras, lo cual lleva a la clarificación de intereses y expectativas en correspondencia con los de estas figuras (Super citado por Osipow, 1990).

Padres y madres modelan a sus hijos e hijas una serie de conductas, roles y tareas asignadas por la cultura patriarcal. Las madres, por lo general, enseñan diversas conductas asociadas a la vivencia del ser mujer que indican que la maternidad es un rol inherente a la condición femenina y por lo tanto que la principal vocación de las mujeres es tener hijos e hijas biológicas o no. Dicho aprendizaje lleva implícita la necesidad de ser para otras personas, aunque esto provoque la anulación de sí mismas, es decir la renuncia a sus intereses, deseos, aspiraciones, y expectativas entre otros.

La entrega, el servicio, la ayuda, y la obediencia son valores que forman parte de la femineidad así entendida y por tanto inciden en las elecciones vocacionales por anteceder al planteamiento de los objetivos y metas que las personas se formulen. Tales valores determinan la conducta al ser criterios básicos para la aceptación o rechazo de una alternativa vocacional, legitimando o no las preferencias y actitudes. Lo anterior puede asociarse a la tendencia de las mujeres para elegir carrera dentro del área de servicios, a diferencia de los hombres quienes tienden a escoger espacios técnicos o directrices (Knichty y Strange citados por Isus,1995).

Se espera que las jóvenes no aspiren a trabajar a tiempo completo, sino que se incorporen a una actividad que puedan dejar fácilmente para casarse, y tener hijos o hijas y puedan dedicarse a tareas familiares (Isus, 1995). Por su parte las figuras paternas contribuyen a reforzar este mensaje e influencian la elección vocacional de las jóvenes en la medida en que definen la relación de las mismas con el mundo público (espacios remunerados). En este sentido, Super citado por Osipow (1990), indica que el autoconcepto académico y social condiciona el análisis de las alternativas, siendo la elección el resultado de adecuar la autoimagen al concepto que se tiene de la profesión elegida. El condicionamiento de la cultura patriarcal hace que algunas mujeres aprendan a dudar de sus capacidades y rendimiento, de ahí que sus aspiraciones y elecciones profesionales se ven limitadas. Sin embargo, indica Lagarde (1995), las mujeres pueden optar por construir una identidad propia conscientes de las decisiones que asumen, la forma en como lo hacen y las consecuencias que las mismas tengan.

En ese sentido, Cordero y otros (1996), agregan que, en la actualidad, las jóvenes pueden asumir dos opciones:

Reproducir la tradición e inclinarse por ocupaciones que respalden el modelo patriarcal, es decir profesiones feminizadas que agrupan carreras de menos prestigio social, menos tecnificadas y remuneradas.

O bien optar por nuevas experiencias adentrándose en el mundo de la ciencia y la tecnología, es decir, incorporarse en ocupaciones que han sido masculinizadas, aunque tengan que enfrentar barreras sexistas para abrirse un espacio dentro de un contexto que subestima la capacidad intelectual y creativa de las mujeres.

En Costa Rica, el sistema educativo ofrece a la población adolescente dos opciones que estimulan el desarrollo vocacional. Ellas son: la formación académica con un bachillerato generalista en secundaria, o la educación técnica y profesional. Esta última representa una alternativa para propiciar la incorporación de hombres y mujeres al campo laboral, fortalecer la formación integral, promover el desarrollo personal y social con el objetivo de estimular la integración exitosa como profesionales 
en el sector productivo, así como la posibilidad de continuar estudios a nivel superior. Este sistema ofrece la especialización en ocupaciones tanto tradicionales como no tradicionales para hombres y mujeres.

Actualmente se está desarrollando el proyecto "Implementación de políticas de género en Colegios Técnicos Profesionales y Académicos con Valor Agregado" cuyo propósito es incrementar la participación femenina en especialidades "masculinizadas". Este proyecto, que cuenta con el apoyo económico de la Comunidad Económica Europea, es un gran aporte para fortalecer las bases de la igualdad de oportunidades entre mujeres y hombres en relación al acceso a las diferentes especialidades que ofrecen los Colegios Técnicos. Dicho proyecto se desarrolla en siete Colegios Técnicos, que han invitado a las jóvenes a profesionalizarse en áreas no tradicionales enfatizando en Electromecánica (Telecomunicaciones, reparación de teléfonos) e Informática. Este proyecto también impulsa acciones para concientizar a la Comunidad Educativa y a los entes empleadores sobre la importancia de la participación femenina en estos espacios así como los requerimientos necesarios para su desempeño eficaz. Plantea el fortalecimiento de los programas de Orientación Vocacional a través de talleres exploratorios que permitan a las jóvenes experimentar la realidad profesional. Estos espacios pueden representar para las jóvenes la posibilidad de concretar la cristalización de una preferencia vocacional.

\section{Acercamiento metodológico}

Para esta investigación, enmarcada en el enfoque de investigación cualitativa, se utilizó el método fenomenológico para sistematizar el acercamiento al tema de estudio así como la recolección y el análisis de la información. Según esta corriente filosófica, la verdad se encuentra en la existencia del ser humano de ahí que se hace referencia a una red de significados que definen una postura y forma de entender la realidad, por ende no se encuentra una verdad absoluta (Dobles y otros, 1996).

Se eligió la modalidad de investigación cualitativa por la importancia que le otorga a la comprensión de los significados que las personas dan a su propia realidad y a su situación cotidiana. "La perspectiva cualitativa representa un recurso de aprehensión de una realidad cuyos significados de otra forma, no serán accesibles ni comprensibles" (Camacho y Pardo, 1994, p. 23). $\mathrm{Al}$ respecto Taylor y Bodgan (1990), destacan la importancia de profundizar en el significado que las personas le dan a sus vivencias, y además al hecho de no perder de vista que las actuaciones son el producto del modo en que cada quien define el mundo.

Para el desarrollo de la investigación se siguió el siguiente procedimiento metodológico: en primer lugar se realizó la investigación bibliográfica sobre la temática con el fin de asumir una posición teórica de partida así como la clarificación de los ejes temáticos del estudio.

Se escogió posteriormente la entrevista a profundidad como la técnica más adecuada para la recolección de los datos; este tipo de entrevista responde a la formación profesional de las investigadoras y permite apoyar a las jóvenes en aquellas experiencias que se encuentran en proceso de aceptación.

Para la realización de las entrevistas se definieron los siguientes focos temáticos:

1. Concepto de mujer y femineidad.

2. Autopercepción como mujeres adolescentes.

3. Roles o funciones de las mujeres.

4. Modelos femeninos y masculinos.

5. Concepto de trabajo femenino.

6. Rompimiento para realizar la elección.

7. Proceso de elección.

8. Experiencia como mujer estudiante. de colegio técnico y especialidad.

9. Expectativas futuras. 
Se realizaron entrevistas a nueve estudiantes de tres Colegios Técnicos que ofrecen las especialidades de interés en este estudio:

a. Colegio Técnico Profesional Industrial de San Sebastián con dos estudiantes, una de la especialidad de Electrónica Industrial y la otra de Electromecánica.

b. Colegio Vocacional Monseñor Sanabria con cinco estudiantes en total, de las siguientes especialidades: Electrónica en Reparación de Equipo de Cómputo, Mecánica Automotriz, Mecánica de Precisión, Mecánica General y Microelectrónica.

c. Colegio Técnico Profesional Industrial de Calle Blancos con dos estudiantes: una de ellas estudia Refrigeración y Aire Acondicionado, y la otra Construcción Civil.

Para la selección de las jóvenes y la organización logística se solicitó ayuda al Departamento de Orientación de las instituciones educativas. Los criterios de participación utilizados fueron los siguientes: 1. Ser mujer estudiante de las especialidades seleccionadas para este estudio. 2 . Tener interés en la investigación y 3. Disponer de tiempo para asistir a las sesiones de entrevista. Estas se realizaron en horario extraclase en las instalaciones del colegio respectivo.

Una vez realizadas las entrevistas, se procedió a efectuar el análisis de la información a través de la triangulación de los datos con los postulados teóricos. Este procedimiento permite, según Bogdan y Taylor (1990) confirmar la validez de los datos protegiéndolos de las tendencias de las investigadoras y, por ende, alcanzar una mejor comprensión de los significados que las jóvenes dan a su experiencia de vida.

\section{Discusión de resultados}

Esta sección recoge el análisis realizado a partir de la información que aportaron las participantes en el estudio. Con esa información se dio respuesta a las preguntas de investigación planteadas. Estas sirvieron de guía para la presentación de los resultados de la investigación.

\section{a. El ser mujer y la femineidad}

Las adolescentes entrevistadas al referirse a la femineidad le atribuyen a las mujeres una serie de características y condiciones socioculturales comunes sustentadas en la ideología patriarcal. Al mismo tiempo anotan otras características que trascienden la concepción tradicional de mujer. Para ellas, la femineidad integra aspectos un tanto contradictorios entre sí y por ello, las jóvenes se debaten entre el ser "mujeres tradicionales y mujeres contestatarias" al mismo tiempo.

Para ellas, la visión tradicional de mujer busca el que las mujeres se conciban a sí mimas como: seres sumisos que requieren de control y de ser limitadas por los demás; objetos de dominio sexual masculino, cuerpos para admirar, seres con menor fuerza física que los varones. Ante esta realidad, las mujeres en la cultura patriarcal, según ellas, deben cumplir y reproducir el mandato matrimonial, ser esposas obedientes a los maridos; ser madres $\mathrm{y}$ atender las necesidades emocionales y permanecer en la casa atendiendo las necesidades del hogar y la familia.

"Yo pienso que el sueño de toda mujer es casarse, sí, formar una familia... mi mamá nunca ha trabajado, bueno trabajó hace muchos años y ahora no, y entonces ella tiene que estar dependiendo de mi papá que si necesita algo tiene que esperarse hasta que mi papá llegue y le dé plata y vaya a comprarlo. Tal vez mi papá no tiene y entonces ella tiene que privarse de muchas cosas porque tiene que estar dependiendo de un sueldo y es algo que a mí no me gusta, porque yo siento que mi mamá se merece muchas cosas, mi mamá ha hecho muchas cosas por nosotros" (Entrev. F). 
"La principal función de la mujer yo creo que es ser madre... Ser madre y darse a valer, como es, y no que la tengan como un objeto sexual, sino que sea algo así diferente" (Entrev. C).

"Yo diría que lo primero es ser madre y la segunda dar la parte sensible a las cosas. Porque muchas veces la razón es importante pero hay decisiones que no se pueden tomar con respecto a razones o a lo que es correcto o incorrecto, muchas veces uno tiene que ser imparcial" (Entrev. E).

Las jóvenes especifican que en la construcción de la identidad tradicional femenina juega un papel importante el ejemplo de otras figuras femeninas que las estimulan a valorar el matrimonio basado en relaciones asimétricas y la maternidad como negación de la individualidad. Este mandato, para Bolaños (1993), lleva a las mujeres a responder a un "deber ser" impuesto, estando sujetas a compartir desde ahí la comida, techo, sueños, y servir a los hombres quienes se encargan del mundo público en el cual gozan de poder, éxito, dinero, conocimiento, así como de la posibilidad de independencia.

Ante este modelo de mujer tradicional, las jóvenes rescatan otra faceta del ser mujer, la dimensión racional y el desarrollo intelectual de las mujeres, y hablan de "la mujer profesional", donde ésta desarrolla tanto las capacidades que les permitan responder al mundo laboral, como la diversidad de intereses personales y la maternidad.

\footnotetext{
"Yo pienso que la mayoría de mujeres aspiran a desarrollar el instinto materno y laboral que tienen y ser mujer al mismo tiempo... por circunstancias económicas tienen que trabajar, la mayoría quiere ser madre, es como natural, pero criar a un hijo y tener una profesión es muy difícil. Además de que uno sigue siendo cuidadosa y racional. Todo esto es aplicado al campo laboral y a cualquier campo, que tiene que mantener una familia, hijos, ..." (Entrev. A).
}

Para atender en forma simultánea ambas funciones, estas jóvenes apelan a un cambio significativo en la mentalidad social que se refleje en acciones concretas en cuanto al desempeño de los roles, labores y funciones que cumple cada género.

\section{b. Motivaciones y retos personales en la elección de especialidades "no femeninas"}

Las jóvenes participantes en este estudio reportan una serie de motivaciones que alimentaron su interés por ingresar a la Educación Técnica y a especialidades "no tradicionales" para las mujeres:

El ingresar a la Educación Técnica y sacar una especialidad es la oportunidad para ingresar al mundo laboral al finalizar la secundaria y financiar la educación superior futura:

Es claro en las jóvenes el deseo de trascender la concepción de mujer tradicional, de ahí que las mismas anhelan complementar su preparación académica y técnica con estudios a nivel universitario para desempeñarse como mujeres profesionales. Encuentran en la Educación Técnica la posibilidad de tener la preparación básica para trabajar y así financiarse los estudios superiores al tiempo que adquieren mayor independencia económica y laboral. Para algunas de las participantes el campo no tradicional es más atractivo por ofrecer opciones laborales y salariales.

"Si yo salía de un colegio académico, salía con un Bachillerato pero no con una posición laboral, sino que si quería trabajar lo tenía que hacer en una tienda o en una fábrica, entonces yo pensé más que todo en el futuro, poder mantenerme, ahí le abren a uno otras perspectivas. Uno sale con una carrera técnica y dan más opción para trabajar y poder estudiar porque uno tiene un sueldo fijo que la hace ser más firme económicamente y uno puede independizarse más rápido” (Entrev. B).

El factor económico representa para las jóvenes un elemento determinante tanto para ingresar a un colegio técnico como para elegir una especialidad. En ese sentido se coincide con Rivas (1995), quien señala que las demandas económicas se han convertido en un aspecto determinante al elegir una ocupación u oficio; de ahí que en muchas ocasiones los jóvenes y las jóvenes 
busquen la estabilidad económica más que el responder a sus intereses y capacidades vocacionales.

Una especialidad técnica "no tradicional" ofrece la opción para desarrollar habilidades, actitudes y alcanzar intereses personales.

Se observa en las participantes la necesidad de dar a conocer y explotar sus habilidades centrándose fundamentalmente en el plano racional y de lógica matemática. En algunos casos esta exploración fue decisiva en el momento de tomar la decisión vocacional y cristalizar la preferencia en cuanto a la Especialidad.

"Cuando yo estaba en noveno la especialidad que me llamaba la atención era Precisión. Yo me ponía a ver a los compañeros trabajar y siempre me iba a meter al Taller, me acuerdo que yo me había matriculado en Secretariado, pero me dí cuenta que yo no era para eso, un trabajo tan monótono y no sé, esa área de empleo ya está muy saturada para las secretarias. El profesor me llegó a decir por qué se metió ahí, usted no era que quería precisión y él me podía ayudar para que lo hiciera y me pasé porque respondía más a lo que yo quería” (Entrev. A).

"Bueno primero fue Dibujo Arquitectónico y dibujar cosas es muy lindo, y la construcción lo vi muy bonito. Mi mejor amiga entró a Informática y ella quería que entráramos juntas, me sonaba bonito porque ahora la tecnología es lo máximo. Me puse a pensar que no tengo computadora y que era algo que no me llamaba mucho la atención. En cambio en construcción hay planos y tengo que dibujar, allí está el dibujo arquitectónico, puede ser topografía, también hay Autocad y puedo dibujar en computadora. Encontré que en construcción se abarcan más campos, porque vemos computación, dibujo arquitectónico, topografía y lo relacionado con refrigeración y electricidad... Se usa mucho la matemática y la fisicomatemática y eso me gusta mucho" (Entrev. H).

"Bueno, este ... La decisión de mi parte fue fácil porque yo siempre he sido una persona que me gusta hacer cosas diferentes. El problema fue un poquito en mi casa. Porque, bueno, mi mamá cuando yo le dije, bueno yo no quería entrar a electromecánica y a lo que quería era a mecánica automotriz, y bueno fue un relajo, en mi casa mi mamá me empezó a gritar y me decía que yo siempre creía que era hombre, que ¿cuándo iba a aprender a hacer cosas de mujer?, que yo siempre trataba de tener una competitividad con los hombres y que eso no me iba a llevar a nada" (Entrev. I).

Está presente en las jóvenes la necesidad de romper con los estereotipos de masculinidad y femineidad impuestos por la cultura y fortalecidos por la educación. Los mismos han hecho que se le asigne a los hombres la tarea de desempeñar con mayor propiedad la dimensión instrumental o lógica mientras que a las mujeres se les asigna lo afectivo y lo concreto (Barberá en Fernández, 1998).

Junto a la oportunidad que las jóvenes hallan en las Especialidades para poner en práctica sus destrezas e intereses vocacionales; se evidencia en ellas una serie de características personales, que las capacitan para "sobrevivir" en este tipo de ambiente. Entre estas características se encuentran: ser emprendedoras y responsables, tener la capacidad de enfrentar retos, de lidiar con la ambigüedad y hasta con el rechazo.

"A veces estamos analizando una falla en un auto y
ellos buscan, no sé, una vez nos pasó con un carbura-
dor y estábamos quitando unas piezas y estábamos
dándole más a una parte y todo el mundo así ... por-
que no salía, entonces les digo yo ¿por qué no sacamos
ese pedacito? Y se quedaron todos así jverdadi y em-
pezaron: no, no eso no se saca. Yo le dije que si, que
probábamos nada se pierde. Al principio se quedaron
así con cara de no, no... pero al final de cuentas sí ha-
bía que quitarle esa piecita" (Entrev. G).

"El profesor me dijo: "no crea que usted por ser mujer todos la van a ayudar". Y yo le dije: vea, profesor, cuando yo entré aquí no era por el hecho de que solamente yo mujer entre tantos hombres, cuando yo entré a esta especialidad yo lo hice porque creo que puedo hacer las cosas sola y no crea que eso va a suceder. Entonces él se quedó callado y como yo soy dada a lo sentimental eso se me dio mucho. Pero ya los de sexto de precisión me ayudaron mucho, ellos me apoyaban, era un grupo un poco desordenado pero ellos me respetaban mucho, eso era lo que más me gustaba de ellos" (Entrev. A).

Estas características de personalidad han sido reforzadas a través de las relaciones 
que las jóvenes establecen con los modelos maternos a quienes identifican y definen como mujeres valientes, fuertes y poco tradicionales. En general, estas figuras maternas son un tanto contradictorias, por un lado les estimulan a las hijas la independencia y el coraje, mientras que en otros momentos les refuerzan los roles femeninos tradicionales.

"Es que la mamá le enseña a uno tantas cosas y bueno le pongo por ejemplo a mi mamá, que siempre ha sido cabeza de hogar y nos ha enseñado a nunca echarnos para atrás por más difícil que sea el camino, por más obstáculos que tenga, que siempre tengamos una sonrisa, que todos los sueños que tengamos no queden en fantasías sino que tratemos de realizarlos. Y que, diay, la mujer puede trabajar en cualquier cosa y que no solamente que porque ese trabajo es de hombre usted no lo puede realizar... Mi mamá tiene una finca en Pérez Zeledón y mi mamá pagaba peones pero era muy hiperactiva y ella también se ponía a chapear y yo decía qué increíble, y siempre llegaba alguien nuevo a la finca y le decía lo linda que estaba y que era una mujer la que la tenía a cargo. Yo ahí me daba cuenta del esfuerzo que hacía y que hizo que mi mamá fuera una triunfadora y con lo que hace, a uno le enseña las cosas" (Entrev. A).

"Mi abuela es una persona que es muy sabia y es una persona sumamente feminista. Ella cree que la mujer es mejor que el hombre y ella en ese caso más bien se pasa la línea, pero eso ayuda mucho porque la mujer siempre vive encerrada y dice: no puedo hacer ciertas cosas porque soy mujer. Pues mi abuela siempre me ha dicho: jtú puedesi. Y ella sostuvo su hogar sola y crió siete hijos, sola, trabajó increíblemente para lograr lo que ella quiso, que era que sus hijos estudiaran, que todos sus hijos se desarrollaran como profesionales y lo logró, a pesar de que ella no estudió" (Entrev. I).

No obstante, al ingresar a este espacio educativo las jóvenes carecen del entrenamiento previo que por ser hombres sus compañeros han recibido desde niños. Ellas no han tenido oportunidades para familiarizarse con el desarrollo de habilidades motoras gruesas, con el lenguaje técnico y con el dominio de un ambiente o espacio tradicionalmente definido masculino.
"Es cierto a las mujeres les cuesta un poquito más, al principio, porque el hombre tiene la ventaja que desde que es pequeño sabe lo que es el alicate, lo que es el martillo, lo que son muchas cosas, y no es cualquier mujer que lo sabe. O sea, tiene que tener una trascendencia para poder conocer eso, entonces al principio cuando entra no sabe ni siquiera qué es un martillo y ahí empieza el problema. Uno tiene que pasar un período para desarrollar uno mismo las actitudes y las actividades. Tiene que como pasar una etapa de inestabilidad para encontrar uno las habilidades escondidas" (Entrev. I).

En estas ideas se encuentra coincidencia con el planteamiento de Barberá (en Fernández, 1998), al indicar que la división sexual que realizan las sociedades patriarcales, estimula en los hombres el dominio, la objetividad y competencia, mientras que para las mujeres se les entrena para la expresión de la afectividad, la calidez y la sensibilidad ante las necesidades de otras personas.

\section{La educación técnica y una especialidad} "no femenina" da oportunidad a las jóvenes de obtener reconocimiento y prestigio.

Como parte de las necesidades propias de la adolescencia, las jóvenes requieren fortalecer la percepción que tienen de sí mismas, clarificar su rol y posición como mujeres jóvenes. El grupo de participantes percibe la Educación Técnica y la escogencia de una especialidad "masculinizada" como el espacio idóneo para cumplir tareas que les permitan reforzar su valoración personal y obtener reconocimiento por parte de personas significativas. A través de este proceso, las jóvenes replantean su identidad femenina y vocacional. Esta necesidad les ha hecho optar por nuevas experiencias e incorporarse en especialidades que han sido masculinizadas, aunque esto implique el enfrentar barreras sexistas para abrirse un espacio dentro de un contexto que subestima la capacidad intelectual y creativa de las mujeres (Cordero y otros, 1996).

El deseo de ingresar a este tipo de institución y obtener un título prestigioso 
es fuerte para el grupo de participantes quienes, en muchos casos, antepusieron ese interés al conocimiento previo que debían tener de la Especialidad a la hora de elegir. Esto hizo que las mismas se enteraran de aspectos elementales de la Especialidad una vez admitidas en la misma.

"Yo no sabía lo que era Mecánica General; cuando yo entré el primer día el profesor empezó a hablarnos de electrodos y perlin, y yo más perdida. Esperaba que nos enseñaran qué era eso pero. Ellos le dan a uno un folletillo y ahí venía Mecánica General y decía más o menos qué era. En la visita que uno hace y con los folletos que dan a mí me llamó la atención y más que me dijeron que si yo la llevaba podía entrar a INTEL." (Entrev. D).

Aunque las jóvenes se perciben como personas capaces de realizarse eficientemente tanto en el área académica como laboral, reciben mensajes descalificantes que cuestionan su eficacia; esos mensajes son dados por amistades, novios, compañeros, compañeras, profesoras y profesores.

"Yo tengo un compañero que es demasiado machista y él me dice siempre "a mí no me pongan a hacer trabajos con mujeres porque después termina uno haciéndolos solo". La primera vez que me pusieron a trabajar con él traté de hacer lo máximo para que no me dijera nada y no me dijo nada. Yo sentí que hice mi trabajo bien pero él siempre decía, icon mujeres no, a mí no me pongan con mujeres! Ya que como ha ido poco a poco asimilando que nosotras somos compañeras y que también podemos cumplir el mismo papel que ellos... También tengo un amigo que estudió soldadura y él me dice ¿Qué cuándo voy a su casa a ver los manís que hizo, cuándo hacemos una competencia para ver quién solda mejor?; o cosas asî" (Entrev. D).

Estas descalificaciones en opinión de Almanza y otras (1997), hacen que en la elaboración de su identidad, las adolescentes vivan contradicciones con respecto a su "deseo de ser" y el "deber ser" que es impuesto por la cultura patriarcal y que hace que las mismas se preparen para cumplir roles impuestos (rol materno, rol de custodia moral: cuido y atención de otras personas), posponiendo así la satisfacción plena de sus deseos y necesidades como mujeres.

Se refuerza con ello el planteamiento de Wood (1999), para quien las mujeres jóvenes son valoradas en las situaciones donde se desenvuelvan de forma silenciosa y complaciente; mientras que los hombres son estimulados por el esfuerzo académico y las habilidades para reconocer sus intereses. Por ello, estas jóvenes deben trabajar muy fuerte para demostrar su capacidad y eficiencia, ya que, de una u otra manera está en duda ahora como estudiantes y en un futuro como trabajadoras por el hecho de estar entrando a un espacio que tradicionalmente les ha sido negado.

Una especialidad no tradicional para las mujeres les permite la oportunidad de desenvolverse en ambientes masculinos que no dejan de ser hostiles para ellas.

Otro aspecto que refuerza la participación de las adolescentes en Especialidades "masculinizadas", es la "familiaridad" que tienen las mismas para desenvolverse en el mundo masculino; desde niñas han estado enfrentando barreras y tratando de replantear su relación con hermanos, primos, padres y/o compañeros.

“A mí me gustaba más jugar con mi hermano... eso tal vez por la confianza que uno tiene en ellos, uno a veces va a jugar con amigas y no sabe el gusto que tienen y que por "x" razón se enojan. En cambio a mi hermano yo sé qué es lo que le gusta y lo que no, y trato de evitarlo, con las amigas uno no sabe lo que esperan. Soy una persona que me he criado entre hombres. En mi familia, mi papá son seis hombre, y en mi mamá son cinco hombres y ella. Entonces yo siento que yo me he criado entre hombres y ya con mis tíos ha sido diferente, porque si ellos ocupaban que yo les ayudara a arreglar ellos me llamaban... Yo fui la primera mujer de la familia y se puede decir que ellos me influenciaron demasiado" (Entrev. D).

La relación de "cercanía” que algunas de las participantes mantienen desde niñas con las figuras paternas es otro 
factor que contribuye a que las mismas crean que el interactuar en un ambiente masculino no presenta inconvenientes significativos para su satisfacción personal y ocupacional. De acuerdo con Pipher (1997), las figuras paternas refuerzan la elección vocacional de las jóvenes en la medida que definen la relación de las mismas con el mundo público o espacios tradicionalmente definidos como masculinos.

Sin embargo, en su proceso de desarrollo las jóvenes han experimentado circunstancias que las llevan a "distanciarse" y a debilitar la relación que mantenían con sus padres; situación que podría tener relación con la necesidad que las adolescentes tienen de involucrarse en ambientes masculinizados en busca de protección y aprobación, aunque experimenten ambigüedad al recibir rechazo.

Otro aspecto importante se refiere a las oportunidades que ofrecen los "ambientes masculinos" en cuanto al manejo de la libertad, la opción de involucrarse en actividades sociales compartiendo con los jóvenes varones; representa una fuente de motivación importante para las jóvenes a la hora de elegir la rama técnica y la Especialidad.

Aunque las jóvenes sabían que este tipo de Especialidades contaba con poca participación femenina, y a pesar de ser conscientes de que pueden moverse con facilidad en ambientes masculinos, al darse cuenta que son las únicas mujeres en grupos de quince o más hombres, experimentaron sentimientos de ambivalencia y de reto que les cuestionaron en un inicio su elección vocacional y las posibilidades de éxito, ya que esta situación las enfrentó a la competencia con los varones en situaciones de desventaja.

$\mathrm{Al}$ ingresar a estos grupos de varones ellas continúan lidiando con estereotipos sexistas que ponen en duda el valor de las mujeres y reproducen el concepto tradicional de mujer. Estas jóvenes se mueven constantemente en una gran contradicción: entre la aceptación y el rechazo; entre la valoración y la agresión; entre intentar ser excelentes estudiantes y no ser las mejores; entre el ser dependientes y buscar la ayuda; entre el ser respetadas y el ser acosadas; entre el competir y el ser reconocidas y aceptadas; entre el confiar en sus propias capacidades y ser retadas a mantenerse en especialidades femeninas.

Al mismo tiempo que ellas están lidiando consigo mismas por integrar la dimensión racional y así visualizarse y realizarse como mujeres integradas, están lidiando con familiares, novios y amistades para que las reconozcan como tales.

Con respecto al desempeño académico y laboral, la cultura patriarcal, representada por todo el ambiente socio laboral que enfrentan las jóvenes, refuerza constantemente en ellas la necesidad de contar con la compañía y protección masculina como principal medio para desarrollar sentimientos de valoración y seguridad, así como de aceptación personal y social. Lo cual podría inducir a jóvenes a esmerarse por alcanzar la aprobación y reconocimiento masculino.

"Son muy cariñosos, muy amigables, ellos me ayudan
mucho a la hora, digamos que están pendientes de lo
que yo ocupe para ayudarme, también entre ellos son
muy así, pero como lo ven a uno tal vez diferente en-
tonces están encima de uno. Son como muy apegados
a mí, entonces ellos llegan y hablan mucho conmigo,
vacilan mucho y son muy amigos, la relación de amis-
tad se ha hecho muy grande entre nosotros. Uno se
siente como muy querido, muy apreciado por los de-
más. Ellos me lo han sabido demostrar muy bien y el
profesor como que está muy orgulloso de tener a una
mujer, entonces él como que trata de reiterar el es-
fuerzo que yo hago, porque a veces hay cosas en las
que soy mejor que ellos... Entonces él trata de decir-
les ¡Ella es mejor que ustedes!, para que ellos se den
cuenta de que yo, por ser mujer no quiere decir que
no sea apta para el trabajo" (Entrev. F).

En el contexto académico y laboral estas jóvenes deben estar muy alertas ya que son sometidas a pruebas de eficiencia constantemente al mismo tiempo que son discriminadas para ciertas tareas por el hecho de ser mujeres. No se confía fácilmente en la 
intuición de ellas para la solución de problemas propios de la especialidad.

"Ser mujer adolescente es la parte difícil; al menos yo al estar llevando esta carrera, de Reparación de Equipo de Cómputo mis compañeros pasan como puña: a veces dicen no, no, usted que hace aquí? ya usted nada que ver. Ahora estaban desarmando un montón de monitores y había un tornillo que estaba como socado, entonces llega un compañero y me dice ¿cuánto quiere apostar a que usted no lo hace? Y le dije yo, ¿me está retando? a mí no me reta porque usted no sabe con quién se está metiendo y entonces agarré el desatornillador y le safé el tornillo. Entonces me dice, "juepuña, me demostró realmente" y le hago yo sé y es más no es simplemente porque tenga que demostrárselo sino porque yo sé como son las cosas y lo que pienso" (Entrev. D).

La agresión sexual es otra de las condiciones que el ambiente masculino de las especialidades impone a las jóvenes participantes. Ellas han enfrentado experiencias de acoso sexual de parte de profesores y compañeros ante las que desarrollan mecanismos para protegerse. Entre esos mecanismos se encuentran: considerar el acoso algo natural y propio del comportamiento masculino así como desarrollar actitudes y conductas que van desde la pasividad hasta la agresión verbal.

"Ese profesor me decía ¡mi amor! Y no sé qué, yo le decía profesor mantenga su distancia, hay una relación que usted debe mantener entre alumno y profesor. Yo creo que hay cierta forma de tratar a un alumno, siempre hay una diferencia. Yo le dije, no me gusta como usted me está hablando, era como muy abierto, decía, a todas, casi a todas las muchachas les gustaba, les decía ¡mi amor, linda!, ¡qué linda se ve hoy!, cosas así, cosas que no deben venir de un profesor. Entonces yo hablé con él y me dijo "no sea odiosa, machita, qué le pasa! Yo le dije usted tiene que mantener una posición. Con eso fue suficiente y empezó a respetarme.

Mi profesor me mandaba mucho ahí y yo le decía no me mande ahí, qué necio, y él lo hacía al propio para que yo me defendiera. Él nos enseña mucho, es que él no sólo nos enseña de la especialidad, de la vida y cómo es todo" (Entrev. B).

"Con mis compañeros es un vacilón, digamos, a veces se sienta uno y la enagua se le sube y ellos dicen "miren qué piernón ese" y entonces uno se siente tan acomplejadillo, pero ya el año pasado yo vivía así toda... a mí me molestan con los pechos... pero ya los compañeros lo respetan a uno... Digamos, los de cuarto ya a mis compañeras han llegado hasta tocarlas y ellas no dicen nada. Pero a nosotras las que nos hemos dado a respetar, es que ellos nos molestan y nos abrazan pero nosotras les decimos hasta aquí y ellos nos respetan y dicen: está bien hasta aquí, ya no las molestamos más. En cambio esas muchachas se han dejado más y ya tienen famita" (Entrev. D).

Estas experiencias de agresión dificultan en las jóvenes el proceso de elaboración de la identidad para visualizarse, como lo plantea Lagarde (1995), como personas independientes capaces de ampliar sus roles en espacios jerarquizados y limitantes.

También en su afán de obtener reconocimiento y aceptación, el grupo de adolescentes siente la necesidad de demostrarse y mostrar a otras personas cercanas sus capacidades y potencial. Tienden así a competir y compararse constantemente con otras mujeres y con los hombres.

"Yo creo que se da porque, primero yo le pongo mucho esfuerzo, para demostrarle a todo el mundo que yo puedo; porque cuando yo me metí, mi hermano estudió aquí y estudió lo mismo, Refrigeración y Aire Acondicionado. Cuando yo me metí todo el mundo me dijo ¿por qué me había metido en eso?, que yo por ser mujer no servía, que eso era para hombres, todo ese tipo de cosas. Entonces yo le pongo mucho esfuerzo para demostrarle a todo el mundo que no era así, que yo podía. Que por no ser hombre no me tengo que privar de esas cosas y también porque como personas, sin pensar en el sexo, como personas somos diferentes y para unos se nos torna más fácil unas cosas que para otras. Dios nos da diferentes habilidades a cada uno" (Entrev. F).

"Bueno lo primordial es lo físico... pero que también tenemos más espíritu de lucha y estamos en el mundo del machismo, tal vez tenemos más aspiraciones a que se nos reconozcan las cosas, ser vistas no como objetos sino como algo sumamente relevante" (Entrev. E).

El elegir especialidades no tradicionales para las mujeres, ha enfrentado a 
las jóvenes al cuestionamiento y rechazo de amistades y hasta de familiares más cercanos. Esta situación genera en ellas por una parte inquietudes en torno a la elección vocacional y ante la eficiencia de sus capacidades; por otro lado se enfrentan a sentimientos de confusión, angustia y desmotivación a raíz de las rupturas que dentro de sus espacios deben hacer para mantenerse firmes en la decisión tomada.

"Mami me dijo usted sabe que yo la apoyo a usted en todo. Papi me dijo ¿Qué, está loca?; en ese entonces yo andaba con un muchacho que era negro. Me dice "primero me sale con un negro y ahora me sale con Auto, no usted tiene algo". El me dijo que cómo... Yo tuve que hacer todas las vueltas del Colegio. Yo hice el examen de Auto y él no se dio cuenta, yo entré, es decir fui admitida y él no sabía” (Entrev. E).

Esta desaprobación también es apoyada por los novios quienes en algunos casos realizan comentarios tendientes a cuestionar la femineidad de las jóvenes así como los intereses que estimularon la cristalización de estas preferencias, siendo la relación de pareja un espacio donde las jóvenes confirman su identidad sexual y prueban su capacidad para ser aceptadas.

Las jóvenes al identificar el rechazo ante las elecciones vocacionales de amistades que también incursionan en especialidades no tradicionales, buscan apoyarse en su lucha por abrirse nuevos espacios en el campo laboral y "enfrentar" la discriminación de que son objeto.

\section{Consideraciones Finales}

El ser mujer para este grupo de jóvenes adolescentes, incluye la integración de dos dimensiones femeninas contrapuestas entre sí, que necesariamente producen un gran dilema de vida cotidiana que incrementa la contradicción intrínseca con la edad. Por un lado, está la imagen de mujer madre y reproductora atada al hogar con muy poco margen para construir una vida personal; y por otro lado, se presenta la mujer estudiante, profesional y trabajadora, protagonista en el mundo público.

La conquista del mundo público por medio de la profesionalización y del uso de la razón y el intelecto permite a las mujeres, según estas jóvenes, integrar la maternidad y la dimensión afectiva con la razón y la producción intelectual. Para ellas, el ideal de mujer es poder equilibrar el desarrollo de ambas esferas en un ser integrado.

Estas jóvenes al elegir especialidades técnicas no tradicionales para mujeres, desconfirman los planteamientos de Rivas (1995), Holland (1990) y Roe en Osipow (1990) con respecto a que los patrones vocacionales se modelan y se asocian directamente con las preferencias vocacionales de los miembros de la familia. Todas estas jóvenes rompen con los patrones genéricos vocacionales modelados por sus figuras progenitoras. Ellas no siguen las normas culturales asignadas al sexo que según Super (en Osipow, 1990) son decisivas en el desarrollo vocacional. Sin embargo, se nota un patrón de socialización en este grupo de mujeres, y es el haber sido invitadas por sus padres-varones a participar en sus actividades laborales, deportivas y de recreación en general cuando ellas eran niñas. De esta forma, estas jóvenes tuvieron acceso en su infancia a las actividades, roles y funciones tanto "femeninas" como "masculinas".

Durante la adolescencia, las madres buscan influir en sus hijas con el fin de que éstas mantengan la apariencia y el comportamiento tradicional femenino, aunque estudien especialidades masculinas. Los padres, por el contrario, buscan alejarse física y emocionalmente de ellas y de esta forma les retiran el apoyo y la libertad que les otorgaron en la infancia. Las jóvenes interpretan esta actitud de sus padres como una traición y buscan llenar algunos de estos vacíos en las relaciones con los compañeros varones. Ellos tienen mayor libertad y acceso al mundo público por el hecho de ser varones. Estas relaciones con los varones, 
además de proporcionarles confianza les traen también otras dificultades ya que ellos también representan su competencia académica y profesional; ellos las desafían, las subvaloran y hasta las acosan. A pesar de ser esta situación fuerte para las adolescentes, ellas asumen esos desafíos y se sobre esfuerzan para demostrar sus capacidades y condiciones en un mundo masculino en busca de éxito en la especialidad que han escogido. Tal y como lo plantean Cordero y otros (1996), las mujeres al introducirse en el campo de las ciencias y la tecnología tienen que enfrentar barreras sexistas para poder abrirse un espacio ya que éstas subestiman la capacidad creativa e intelectual de las mujeres.

El ingresar al Sistema de Educación Técnica a especializarse en un oficio reconocido como masculino permite a estas jóvenes la preparación para asumir un trabajo remunerado y así continuar con los estudios universitarios al finalizar la secundaria, aunque no todas piensan continuar estudios universitarios en la misma área de la especialidad que han elegido.

El estudio de una especialidad reconocida tradicionalmente como masculina, les permite a estas jóvenes el desarrollo de capacidades intelectuales, y la consecución de la diversidad de intereses que tienen. El desempeñarse como técnicas en esos campos les permite obtener reconocimiento y prestigio como mujeres no tradicionales al mismo tiempo que tienen que lidiar con el pensamiento sexista que les limita el ocupar puestos en las especialidades por el hecho de ser mujeres. Les preocupa que algunas empresas no las contraten apelando a la carencia de fuerza física o a la dificultad que sería enfrentar un embarazo por las funciones que demanda la especialidad. Esta es una preocupación real que les hace bastante incierto el futuro a estas jóvenes y que las pone a dudar sobre el motivo original de hacer una especialidad, cual es el contar con un salario para continuar los estudios universitarios.
Ante esta realidad, los procesos de orientación vocacional en los centros educativos deben ser ampliados con el fin de que trasciendan el suministro de información sobre la oferta y la demanda académica, e incorporen los aspectos que interactúan en la conducta vocacional: familia, mundo laboral, estereotipos, historia de vida personal, aspecto económico y educativo (Rivas, 1995). Es necesario que las instituciones formadoras y profesionales en orientación en servicio tomen en cuenta el impacto que tienen los estereotipos sexistas en el desarrollo vocacional y en los procesos de elección vocacional-laboral. La perspectiva de género en la orientación vocacional permite la comprensión de la cultura patriarcal, y la construcción de la masculinidad, la femineidad en esa cultura, lo cual facilita la ampliación del panorama para la toma de decisiones vocacionales-laborales que realizan mujeres y hombres. Es necesario también, analizar la organización y estructura del mercado laboral con respeto a las demandas, contratación y retención de la fuerza laboral femenina y masculina.

La comunidad educativa en su conjunto debe participar en la identificación y erradicación de estereotipos sexistas en la acción educativa en general. Debe motivar la construcción de experiencias y propuestas con mayor equidad para la organización y el funcionamiento de la misma comunidad. En los colegios técnicos en particular es urgente que el cuerpo administrativo y docente amplíe la mentalidad y estimule, apoye y no desanime las elecciones vocacionales democráticas de la población estudiantil en general y de las mujeres en particular. El personal docente y las empresas empleadoras deben tomar conciencia sobre las oportunidades laborales organizadas dentro de la estereotipia sexista como un paso para la ampliación de posibilidades de empleo. También es necesario atender las situaciones de acoso sexual en los centros educativos y definir políticas y estrategias para prevenirlo. 


\section{Referencias bibliográficas}

Almanza, Jeannette; y compañeras. Percepciones sobre la femineidad en mujeres de undécimo año del Liceo Monseñor Rubén Odio. Tesis de Licenciatura de la Escuela de Orientación y Educación Especial, UCR. 1997.

Álvarez, Manuel. Orientación Profesional. Barcelona: Cedecs. 1995.

Baró-Martín, Ignacio. Acción e ideología. Psicología Social UCA Editores. 1990.

Bolaños, X. Mujeres, salud y desarrollo con enfoque de género. Comisión Mujer, Salud y Desarrollo O.P.S., O.M.S. 1993.

Bravo, Milagros. “¿Quieren los niños y las niñas ser iguales?" Pedagogía volumen 31. 1996.

Camacho, José A. y Pardo Marta E. Etnografía, Epistemología y cualidad. $R e$ flexiones \# 27 Octubre. UCR: Facultad de Ciencias Sociales, p: 20-31. 1994.

Cordero y otros. Desarrollo de la Identidad y Subjetividad en América Latina. San José: Editorial Costa Rica. 1996.

Delgadillo, Ligia. La mujer en la Universidad: caso Centroamericano. San José: Guayacán. 1996.

Dobles, M. y otras. Investigación en educación. San José: EUNED.

Fernández, Juan. Género y Sociedad. Madrid: Ediciones Pirámide. 1998.
Isus, Sofía. Orientación Universitaria. España: IMPRENTA INO Reproducciones. 1995.

Kourany, Janet, Sterba James y Tong Rosemarie. Femenist philosophies. New Jersey: PRENTICE HALL. 1999.

Lagarde, Marcela. Género y feminismo. España: Horas y horas la editorial. 1997.

- "La identidad de género curso ofrecido en el Centro Juvenil At of Palme”. 1992.

. Democracia de género. Red Latinoamericana de educación popular. México. 1995.

. Una mirada feminista en el umbral del milenio. Costa Rica: Instituto de Estudios de la Mujer. UNA. 1999.

Lamas, Marta. El género: la construcción cultural de la diferencia sexual. México: Grupo Editorial Miguel Ángel Porras S.A. 1997.

Osipow, Samuel. Teorías sobre la elección de carrera. México: Trillas. 1990.

Pipher, M. Reviviendo a Ofelia:¿Cómo salvar a la niña adolescente? Colombia: Norma. 1997.

Rivas, Francisco. Manual de Asesoramiento y Orientación Vocacional. España: Editorial Síntesis. 1995.

Rodríguez. Manuel. La Orientación Profesional. Barcelona: Ariel. 1998.

Suárez, M. Autoestima de la mujer. San Salvador: Fondo de las Naciones Unidas para la infancia. 1989. 
Taylor, J. y Bodgan. R. Introducción a los métodos cualitativos de investigación. Buenos Aires: Editorial Paidós. 1990.

Villarreal, Cecilia. La menopausia: Un proceso de crecimiento. Tesis del Programa de Maestría en estudios de la Mujer. UNA-UCR. 1996.
Wood, Julia. Gendered Lives: Communication, Gender and Culture. Toronto: Wadsworth Publishing Company. 1999.

Zunker, Vernon. Career counseling: applied concepts of life planning. California: Brooks- Cole Company. 1990.

Laura Mora Zúñiga

Docente de la Escuela de Orientación y Educación Especial de la Universidad de Costa Rica e Invetigadora del IIMEC-UCR.

Gabriela Muñoz Porras Docente de la Escuela de Orientación y Educación Especial de la Universidad de Costa Rica, Recinto Paraíso e Investigadora del IIMEC-UCR.

Cecilia Villarreal Montoya Docente de la Escuela de Orientación y Educación Especial de la Universidad de Costa Rica e Investigadora del IIMEC-UCR. 